Research Article

\title{
Performance Evaluation of Seismic Isolation System by Installation Location in Lighthouse Structures
}

\author{
Moo-Won Hur and Tae-Won Park (iD) \\ Department of Architectural Engineering, Dankook University, Yongin, Gyeonggi-do, Republic of Korea \\ Correspondence should be addressed to Tae-Won Park; tw001@dankook.ac.kr
}

Received 5 April 2018; Revised 11 July 2018; Accepted 2 August 2018; Published 24 September 2018

Academic Editor: Ivo Caliò

Copyright (c) 2018 Moo-Won Hur and Tae-Won Park. This is an open access article distributed under the Creative Commons Attribution License, which permits unrestricted use, distribution, and reproduction in any medium, provided the original work is properly cited.

\begin{abstract}
The purpose of this study is to evaluate the applicability of seismic isolation devices for marine accidents under seismic loads. The lighthouse structure is a very important facility when the ship approaches the port. However, it is necessary to reinforce the structure to protect it from earthquake. This study presents isolation technology as a method to enhance the seismic performance of lighthouse structures built before seismic design criteria were established. This paper analyzed improvement of seismic performance in three cases of seismic isolation by applying the proposed method of isolation technology. In Case 1, the entire lighthouse structure is isolated, and in Case 2, only the lighthouse lens, the most important component of the lighthouse structure, has been isolated to assure constructability and economy. In Case 3, isolation effect was analyzed by comparing Case 1 and Case 2 with lighthouse structures.
\end{abstract}

\section{Introduction}

Earthquakes that have occurred several times in different countries are changing the social perception of seismic performance of structures. As observed in the Mexican earthquake (2017) and in Chile (2015), the social and economic damages caused by earthquakes are becoming more serious and reflecting this situation; the seismic standards for social infrastructures such as buildings, bridges, and railways are gradually strengthening. However, lighthouses and docking aid structures, highly regarded as coastal structures, are left almost unprotected against earthquakes without special measures. In the event of an earthquake, if the main arterial roads are destroyed and the supply of supplies to the victims becomes impossible, the sea route is expected to be only the channel. Therefore, the recognition of the safety of coastal structures such as lighthouses should be renewed. Figure 1 shows the damage cases of the lighthouse structures during the Great East Japan Earthquake. As in this case, the lighthouse structure would lose its main function if the damage caused by the earthquake occurs.
Research on seismic retrofitting methods to reduce earthquake damage of structures is continuously being conducted. The seismic reinforcement plan is largely strength reinforcement, ductile reinforcement, and reinforcement method mixed with them. Recently, methods using damping systems and seismic isolation system are increasing. Among them, the seismic isolation system is a practical method to effectively improve the seismic performance of the new structure as well as the existing structure, without damaging the function or the beauty of the structure. It has proven its use in many developed countries (Japan and the United States) that have experienced earthquakes. In the case of the lighthouse structure to be examined in this study, seismic design is simple when applying seismic isolation technology with SDOF structure, and it is advantageous if it is reinforced with seismic isolation technology since it is located independently.

Most existing studies on lighthouse structures have been conducted for the modeling of lighthouse structures [1-3]. Therefore, there are few studies related to seismic performance enhancement and reinforcement plans for lighthouses. Also, the seismic performance of buildings and 
bridges has become a step closer to commercialization due to the many practical applications by the efforts of relevant experts and organizations. However, in the case of the seismic devices of structures such as lighthouse structures and the lens of a lighthouse, it has only a simple guide and has no definite evaluation criterion and design method for each device.

Recent research trends of seismic isolation devices are as follows: Tomita and Fujita [4] studied the threedimensional seismic isolation system, and Auad and Almazán [5] developed a nonlinear vertical locking isolation system. Fujita et al. [6] developed a new method of robustness evaluation for an elastoplastic base-isolated high-rise building considering simultaneous uncertainties of structural parameters.

Maddaloni et al. [7] conducted a shaking table test using recycled rubber equipment, and Shaikh and Kasnale [8] conducted seismic performance evaluation for foundation fixed RC structures and structures equipped with seismic isolation devices. In addition, Dhawade [9] also examined the seismic performance of buildings with fixed foundation and seismic isolation. Previous research has focused on the development of seismic isolation devices and evaluation of seismic performance.

In this study, we propose measures to secure seismic safety of lighthouse structures that are in a defenseless state against earthquakes by proposing a method to apply seismic isolation technology to lighthouse structures. In addition, seismic performance improvement was analyzed by comparing the seismic effect in 3 cases with the nonseismic detailed lighthouse structure using the proposed seismic isolation technique as follows: Case 1, the entire lighthouse structure is seismic-isolated, built before the seismic design criteria were established. Case 2, only the lighthouse lens, that is the most important component of the lighthouse structure, has been seismic isolated to assure constructability and economy. Finally, in Case 3, Case 1 and Case 2 are all applied. This thesis will provide basic data necessary for establishing master plan of seismic retrofit of lighthouse structures using the seismic isolation system.

\section{Application of Seismic Isolation Technology for Lighthouse and Coastal Structure}

The types of seismic devices used in lighthouses and docking aid facilities must use the sliding type rather than the laminated rubber type used in general buildings. As seismic devices of laminated rubber type are difficult to apply to lightweight materials, and in the case of a system using a coil spring, seismic isolation effect is reduced when the weight is changed.

In Japan, high-performance seismic techniques such as seismic isolation have been applied to civil structures such as bridges in the past. However, after the Kobe earthquake in 1995, under the decision that strengthening of seismic design was not the best, the law on "Acceleration of Criteria for Earthquake-Resistant" was implemented, and the efforts and obligations for criteria for earthquake resistance were applied to public buildings. Also, based on this, the seismic isolation of the lighthouse was initiated, and it was found that the total number of applications exceeded 5,000. Representative devices that are currently applied to lighthouse isolation are roller-type isolation, cosine rail isolation, and so on.

Figure 2 shows roller-type isolation, and it consists of a support mechanism of a circular rail, a restoring mechanism by gravity, and a damper mechanism by frictional resistance. This system prevents rollers from moving along the upper and lower rails in the form of an arc, and torsional vibration is not generated by guiding the device by the orthogonal two-direction independent rails. As a result of the time history analysis to verify the performance of the seismic isolation device, it was confirmed that the seismic isolation device can reduce the acceleration input by the earthquake to $1 / 10$ and transfer it to the superstructure.

Figure 3 shows the concept of a cosine rail system (CRS) seismic isolation system, a type of metal roller system, in which a rail roller having a cosine curve shaped side is interposed. During the earthquake, the superstructure moves horizontally and vibrates in the shape of a pendulum, and the restoring force presents its feature by gradient of the roller and the rail. The CRS seismic isolation device has a low coefficient of friction and adopts a viscous damper for securing the damping force.

The lighthouse structure is lightweight and hollowcylinder type; therefore, the suitable seismic isolation device should perform excellent seismic isolation effect regardless of the weight of the load by adopting a kind of pendulum movement by the geometry of the rail and inducing the lengthy period. Also, a safety device must be provided to prevent conduction to cope with high and unstable center positions. Second, in case of applying seismic isolation to a structure such as a lighthouse, the response to the bottom seismic vibration varies depending on the type of ground on which the lighthouse is located, the shape and structure of the lighthouse, and so on. However, when we analyze the case of Japan that experiences many earthquakes, it is desirable to secure the necessary required performance as $1 / 5$ of decrease in the response acceleration to the input acceleration of the lens tower base and a displacement response of about $100 \mathrm{~mm}[10,11]$. Third, in the case of the medium and low-rise structures proposed in the previous study [12], it is necessary to apply 2.5 times or more and 2.0 seconds or more as the period ration of the before and after seismic isolated for sufficient seismic isolation effect.

\section{Analysis of Application Effect of Seismic Isolation Technology}

In this chapter, the seismic isolation design using the method of applying the seismic technique presented in the previous chapter applied to the lighthouse structures built before the seismic design standards were established, and the effect was divided into three cases and compared with the nonseismic structures. Case 1 is that the entire lighthouse structure is seismic isolated, and Case 2, only the lighthouse lens, the 


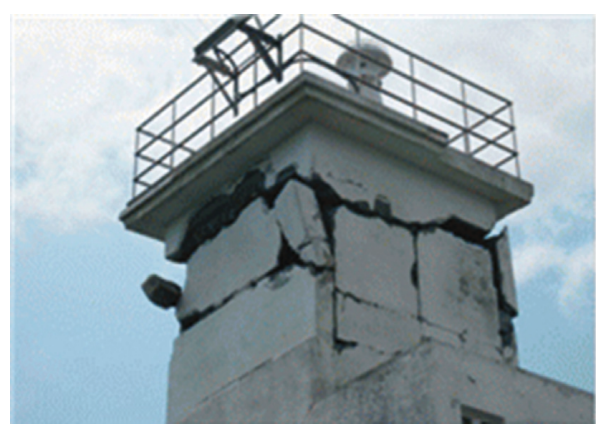

(a)

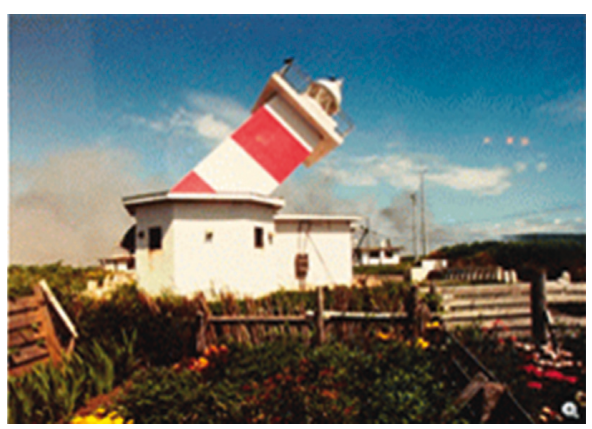

(b)

Figure 1: Earthquake damage of lighthouse (Tohoku Region Pacific Coast Earthquake, 2011).

most important component of the lighthouse structure, has been isolated to assure constructability and economy. Finally, Case 3 is where Case 1 and Case 2 are both applied.

3.1. Structures of Research Subject. The lighthouse structure as a research subject, built in 1980 before the earthquake-resistant design, is an unmanned lighthouse in Gangwon-do, Sokcho, South Korea, and is a five-story reinforced concrete structure. Regarding the strength of structural material, the compressive strength of concrete is $18 \mathrm{MPa}$ and the yield strength of rebar is $300 \mathrm{MPa}$. The first mode period of the lighthouse structure is $0.12 \mathrm{~s}$ before the application of the seismic isolation, and the period after the application of the seismic isolation is designed for $2.0 \mathrm{~s}$ based on the existing research results [12]. The design conditions of the lighthouse are as follows: as a wind loads, basic wind speed $\left(V_{0}\right)$ is $35.0 \mathrm{~m} / \mathrm{sec}$ and roughness is $D$. The seismic load has a zone factor $(S)$ of 0.22 , a site coefficient of $S_{\mathrm{D}}$ $\left(S_{\mathrm{DS}}=0.499 ; S_{\mathrm{D} 1}=0.288\right)$, and an importance factor $\left(I_{\mathrm{W}}\right)$ of 1.2. Figure 4 is an elevation view and a sectional view of the lighthouse structure.

\subsection{Design Load}

3.2.1. Story Weight, Wind Loads, and Seismic Load. The inertial force generated by the earthquake is due to the fixed load, and when the lighthouse structure is sectionalized in 5 stories as shown in Figure 4, the story weights are shown in Table 1.

The transverse loads acting on the structure are largely wind loads and seismic loads, and seismic isolation devices should always remain elastic when wind loads are applied. Since the seismic isolation device may cause usability problems when it is operated under wind load conditions, the wind load acting on the lighthouse structure should be identified and reflected in the seismic isolation device design. To design the isolation system, the dynamic characteristics of the structure before the seismic isolation device is installed and the interaction with the seismic isolation device to be installed should be considered. This is because the behavior of the seismic isolation device may vary depending on the stiffness distribution or the mass distribution of the superstructure. Table 2 shows the wind loads and seismic loads acting on the lighthouse.
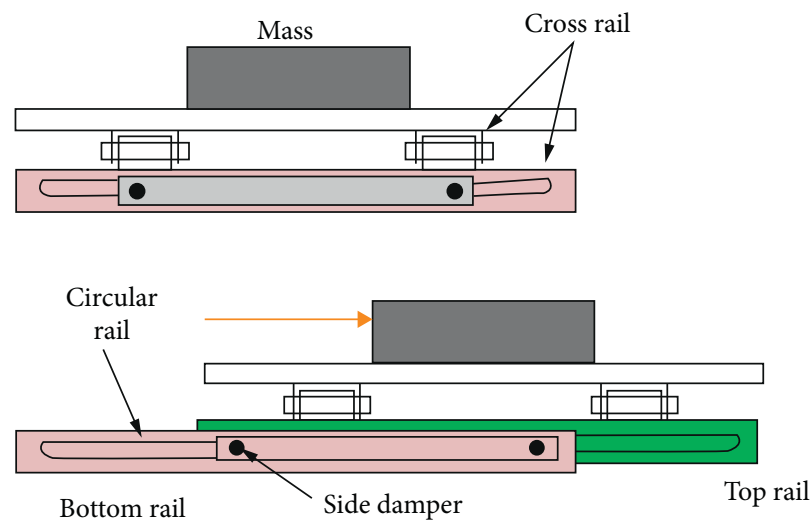

FIgURE 2: Roller-type isolation device.

\subsection{Design and Placement of Seismic Isolation Device}

\subsubsection{Case 1: Seismic Isolation of Whole Lighthouse}

(1) Target Isolation Period. The validity period of a seismic isolation structure is determined using the deformation characteristics of the seismic isolation system, and it must be accompanied to achieve the target isolation that determines the deformation characteristics of the seismic isolation system. The setting of the isolation period is the most advanced step in the design process since it determines the performance of the structure to be designed. The lighthouse structure was set to have an effective isolation period of 2.0 seconds at the design displacement and an effective isolation period of 3.0 seconds at the maximum displacement, as described above.

(2) Determining the Effective Stiffness of a Seismic Isolation System [13]. The effective period of the isolated structure at design displacement $\left(D_{\mathrm{L}}\right)$ and maximum displacement $\left(D_{\mathrm{M}}\right)$ is determined by using the deformation characteristics of the seismic isolation system according to Equation (1). Therefore, it is possible to determine the deformation characteristics of the isolation system to satisfy the target isolation period inversely using the previously set target isolation period. 


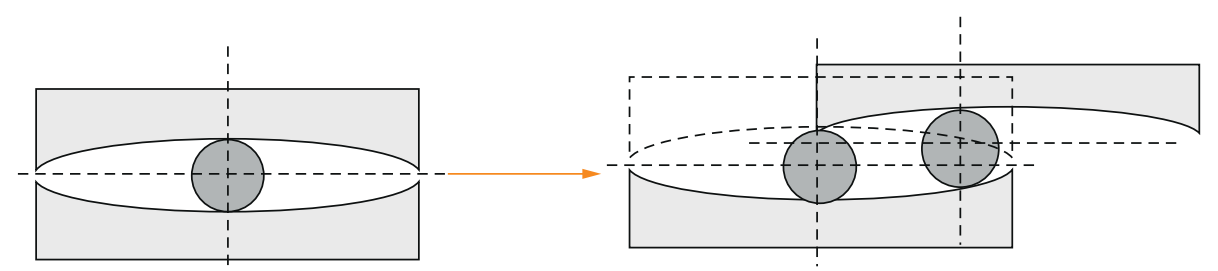

FIGURE 3: Isolation device of cosine rail system.
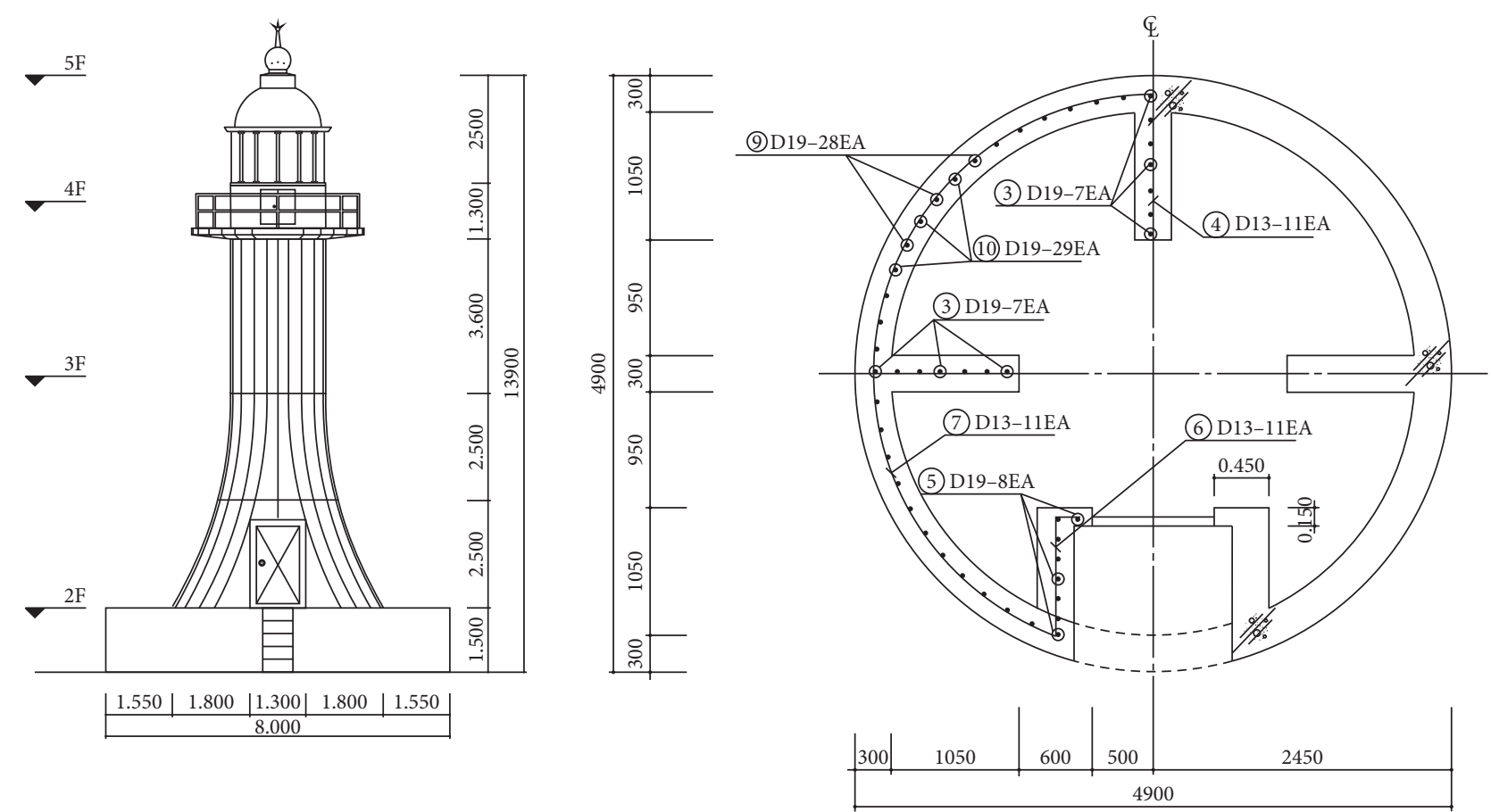

Figure 4: Section and elevation of the lighthouse.

$$
T_{\mathrm{D}}=2 \pi \sqrt{\frac{W}{K_{\mathrm{D}}\left(K_{\mathrm{M}}\right) \times g}},
$$

where $W=$ effective weight of building $(800.0 \mathrm{kN})$; $K_{\mathrm{D}}=$ effective stiffness of seismic isolation system during design displacement; and $K_{\mathrm{M}}=$ effective stiffness of seismic isolation system during maximum displacement.

$$
\begin{aligned}
& K_{\mathrm{D}}=\frac{4 \pi^{2} \times 800}{4 \times 9800}=0.81 \mathrm{kN} / \mathrm{mm}, \\
& K_{\mathrm{D}}=\frac{4 \pi^{2} \times 800}{9 \times 9800}=0.36 \mathrm{kN} / \mathrm{mm} .
\end{aligned}
$$

(3) Seismic Isolation Device Design and Seismic Isolation System Configuration. According to the above conditions, two types of system are used for component of seismic isolation system in this study: lead rubber bearing (LRB) and roller bearing (RB). A total of five elements, one LRB and four RBs, were used for the construction of the isolation system. The combination of such seismic isolation devices is intended to
TABLE 1: Lighthouse story weight.

\begin{tabular}{lcc}
\hline Story name & Story level $(\mathrm{m})$ & Story weight $(\mathrm{kN})$ \\
\hline $5 \mathrm{~F}$ & 13.9 & 6.0 \\
$4 \mathrm{~F}$ & 11.4 & 69.0 \\
$3 \mathrm{~F}$ & 6.5 & 303.7 \\
$2 \mathrm{~F}$ & 1.5 & 421.3 \\
$1 \mathrm{~F}$ & 0 & - \\
Total & & 800.0
\end{tabular}

provide restoration force characteristics while satisfying all conditions such as periodicity and rigidity of the installed seismic isolation system. Table 3 and Figure 5 show the data and hysteresis characteristics of the designed isolation device. Figure 6 shows the shape of the isolator.

(4) Placement of Seismic Isolation Device. As shown in Figure 4, the shape of the lighthouse is a hollow cylinder, and its mass is not sufficient to set the seismic period to the lengthy period and it is difficult to install the seismic isolation system. Therefore, a concrete foundation plate is installed under the lighthouse to facilitate the installation of the seismic 
TABLE 2: Wind load and earthquake load.

\begin{tabular}{lcccccc}
\hline Story & $\begin{array}{c}\text { Story weight } \\
(\mathrm{kN})\end{array}$ & Story level $(\mathrm{m})$ & Story shear $(\mathrm{kN})$ & $\begin{array}{c}\text { Wind load } \\
\text { Overturning moment } \\
(\mathrm{kN} \cdot \mathrm{m})\end{array}$ & $\begin{array}{c}\text { Earthquake load } \\
\text { Story shear }(\mathrm{kN})\end{array}$ & $\begin{array}{c}\text { Overturning moment } \\
(\mathrm{kN} \cdot \mathrm{m})\end{array}$ \\
\hline $5 \mathrm{~F}$ & 6.00 & 13.9 & 0 & 0 & 0 & 0 \\
$4 \mathrm{~F}$ & 68.65 & 11.4 & 0.3 & 0 & 2.4 & 0.7 \\
$3 \mathrm{~F}$ & 303.73 & 6.5 & 6.26 & 14.4 & 29.1 & 67.6 \\
$2 \mathrm{~F}$ & 421.29 & 1.5 & 35.59 & 372.6 & 119.0 & 662.7 \\
$1 \mathrm{~F}$ & - & 0 & 75.09 & & 159.5 & 1000.0 \\
\hline
\end{tabular}

TABLE 3: LRB and RB device details.

\begin{tabular}{lccc}
\hline \multicolumn{1}{c}{ LRB } & & & RB \\
\hline Outer diameter $(L, \mathrm{~mm})$ & 600 & Roller arrangement (upper: a $\times$ b, bottom: $\mathrm{c} \times \mathrm{d})(\mathrm{ea})$ & $($ Upper $) 2 \times 10$ \\
Lead bar diameter $(D, \mathrm{~mm})$ & 100 & Roller size $(\mathrm{mm})$ & $($ Bottom $) 2 \times 10$ \\
Rubber thickness $(\mathrm{mm})$ & 5.0 & Size $(\mathrm{mm})$ & $\varphi 20 \times 50$ \\
No. of rubber layers $(\mathrm{EA})$ & 30 & Using load $(\mathrm{kN})$ & $400 \times 400 \times 140$ \\
Total rubber thickness $(\mathrm{mm})$ & 150 & Maximum load $(\mathrm{kN})$ & 800 \\
1st shape factor $\mathrm{S}_{1}$ & 30 & Axial stiffness $(\mathrm{kN} / \mathrm{mm})$ & 2,000 \\
2nd shape factor $\mathrm{S}_{2}$ & 4.0 & Coefficient of friction & 3,000 \\
Steel plate thickness $(\mathrm{mm})$ & 4.0 & Stroke $(\mathrm{mm})$ & 0.002 \\
Lateral stiffness $(\mathrm{kN} / \mathrm{mm})$ & 0.9 & & \pm 250 \\
\hline
\end{tabular}

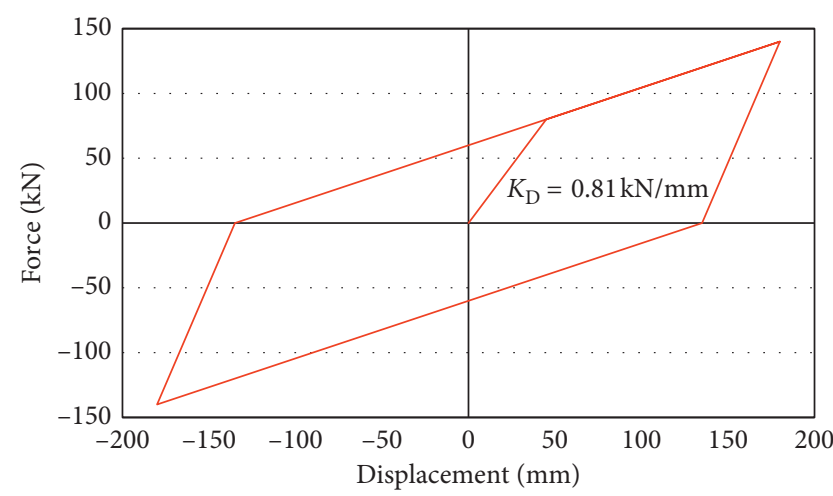

(a)

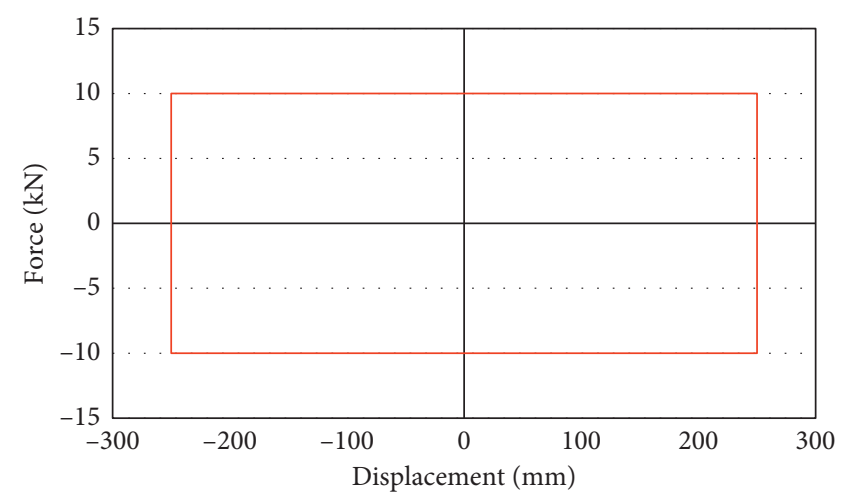

(b)

FIgURE 5: Hysteresis characteristics of the isolation bearing (Case 1). (a) LRB (b) RB.

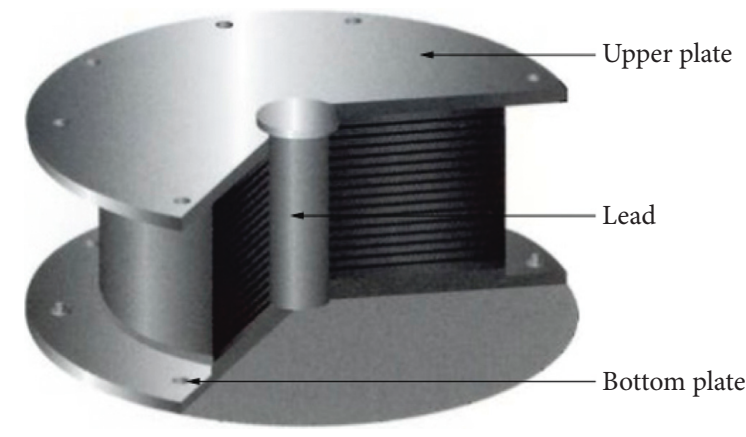

(a)

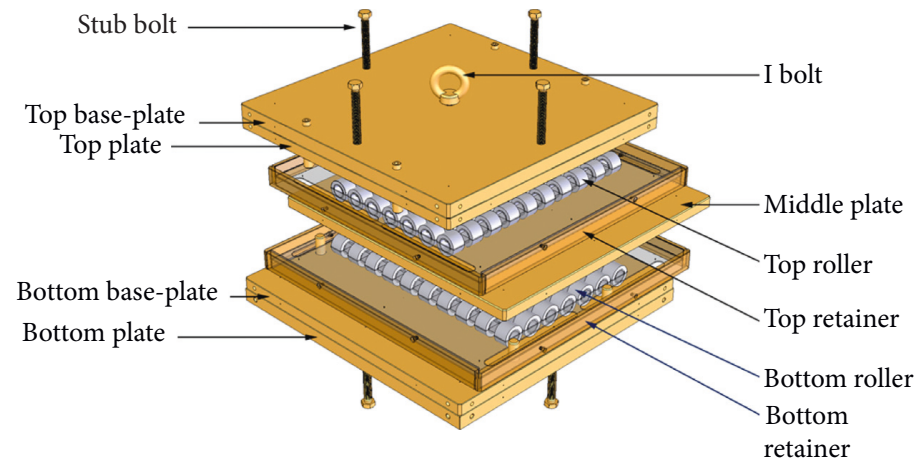

(b)

FIgURE 6: Isolation devices. (a) Lead rubber bearing. (b) Roller bearing. 
isolation device, and as shown in Figure 7 , the $\mathrm{RB}$ is installed on the outside, and LRB having damping force and horizontal stiffness is installed in the center to adjust the period. This arrangement is expected to minimize the effect of twisting by aligning the center of mass and the center of stiffness of the lighthouse structure.

(5) Wind Load Review and Minimum Horizontal Displacement Estimation. Table 4 shows the displacements in the $X$ and $Y$ directions when the wind load is applied. It can be confirmed that the isolation layer does not yield the wind load.

$$
\begin{aligned}
& \text { Isolation layer displacement }=40.6 \mathrm{~mm}<I_{\mathrm{W}} D_{y} \\
& \quad=45 \mathrm{~mm} \text { (yield displacement of isolation layer). }
\end{aligned}
$$

The seismic isolation system shall be designed to withstand the minimum horizontal displacement $\left(D_{\mathrm{D}}\right)$ occurring in the direction of the horizontal axis of the structure in accordance with the following formula:

$$
\begin{aligned}
D_{\mathrm{D}} & =\frac{\mathrm{g} \times S_{\mathrm{D} 1} \times T_{\mathrm{D}}}{4 \pi^{2} \times B_{\mathrm{D}}} \\
& =164.64 \mathrm{~mm}<\frac{D}{2}=\frac{600}{D}=300 \mathrm{~mm} \longrightarrow \mathrm{OK},
\end{aligned}
$$

where $\mathrm{g}=$ acceleration of gravity; $S_{\mathrm{D} 1}=$ design acceleration variables of $5 \%$ damped spectrum in cycle 1 second $(3.4 \mathrm{MA}=0.49742) ; T_{\mathrm{D}}=$ the effective period of the isolated structure in design displacement of direction of consideration ( 2.0 seconds); and $B_{\mathrm{D}}=$ the numerical coefficient associated with the effective damping $\left(\beta_{\mathrm{D}}\right)$ of the seismic system is estimated from Table 5, assuming $20 \%$ effective damping in this example (1.5)

\subsubsection{Case 2: Seismic Isolation of Lighthouse Lens}

(1) Determining the Effective Stiffness of a Seismic Isolation System

The effective period of the isolated structure at design displacement $\left(D_{\mathrm{L}}\right)$ and maximum displacement $\left(D_{\mathrm{M}}\right)$ is determined by using the deformation characteristics of the seismic isolation system according to the following equation. The target seismic period shall be the same as that set in Section 3.3.1. Therefore, it is possible to determine the deformation characteristics of the isolation system to satisfy the target isolation period inversely using the previously set target isolation period.

$$
\begin{aligned}
& K_{\mathrm{D}}=\frac{4 \pi^{2} \times 6}{4 \times 9800}=0.006 \mathrm{kN} / \mathrm{mm}, \\
& K_{\mathrm{D}}=\frac{4 \pi^{2} \times 6}{9 \times 9800}=0.0027 \mathrm{kN} / \mathrm{mm} .
\end{aligned}
$$

(2) Seismic Isolation Device Design and Seismic Isolation System Configuration
According to the above conditions, one type of system is used for component of the seismic isolation system in this study: roller bearing $(\mathrm{RB})$. When the lighthouse lens is surface-evolved, the center of mass and the center of stiffness are integrated, and eccentricity does not occur. Table 6 and Figure 8 show the data and hysteresis characteristics of the designed isolation device.

3.3.3. Case 3: The Lighthouse Structure and the Lighthouse Lens Are Simultaneously Seismic Isolated. In Case 3, the lighthouse is seismic isolated by applying Case 1 and Case 2 presented in the previous section. The target isolation period, effective stiffness, and isolation device configuration adopted both Case 1 and Case 2. We will analyze the effects of Case 1 and Case 2 more clearly through Case 3. The arrangement of the isolation device is shown in Figure 9.

3.4. Isolation Device Reinforcement Construction. The construction of the seismic isolation system reinforcement construction is as follows. As shown in Figure 10, isolation devices can be installed under the whole structure of lighthouse that is already lifted up by the mechanical method. Such a method is commonly used for application of seismic isolation to the low-rise existing concrete structure. According to Figure 8 (Case 2), because only lens becomes seismic isolated, construction can be conducted with readymade and preassembled elements; thus, it would shorten the construction time. In addition, the stopper protects the device from unexpected displacement.

\section{Nonlinear Dynamic Analysis}

4.1. Input Ground Motion. The input ground motion applied to this analysis was selected through a site response analysis. For the site response analysis, we selected bedrock earthquake records from around the world at the PEER Ground Motion Database in the United States. The site condition of the measured site is bedrock $\left(V_{s, 30}>760 \mathrm{~m} / \mathrm{s}\right)$, and in this study, we selected 40 bedrock earthquake records which has 0.3-3.0 scale factor of bedrock spectrum. Site response analysis was conducted for 40 bedrock earthquake records, and then the standard 7 sets of seismic waves that have small deviation between the design response spectrum and the site condition and satisfy (design response spectrum's 1.3 times of $90 \%$ ) the response spectrum are selected through the optimization algorithm. Table 7 shows the input ground motions of the selected seven as above. Figures 11 and 12 show the response spectrum of the design-based earthquake (DBE) of the seismic waves used in the analysis and the acceleration time history of each seismic wave. The analysis was conducted by dividing into the design seismic level and maximum considered earthquake (MCE), and the program used for the analysis was MIDAS GEN 2017.

4.2. Review of Maximum Displacement Response. Table 8 compares the results of the analysis of the maximum displacement response of the seismic isolation of each case and the 


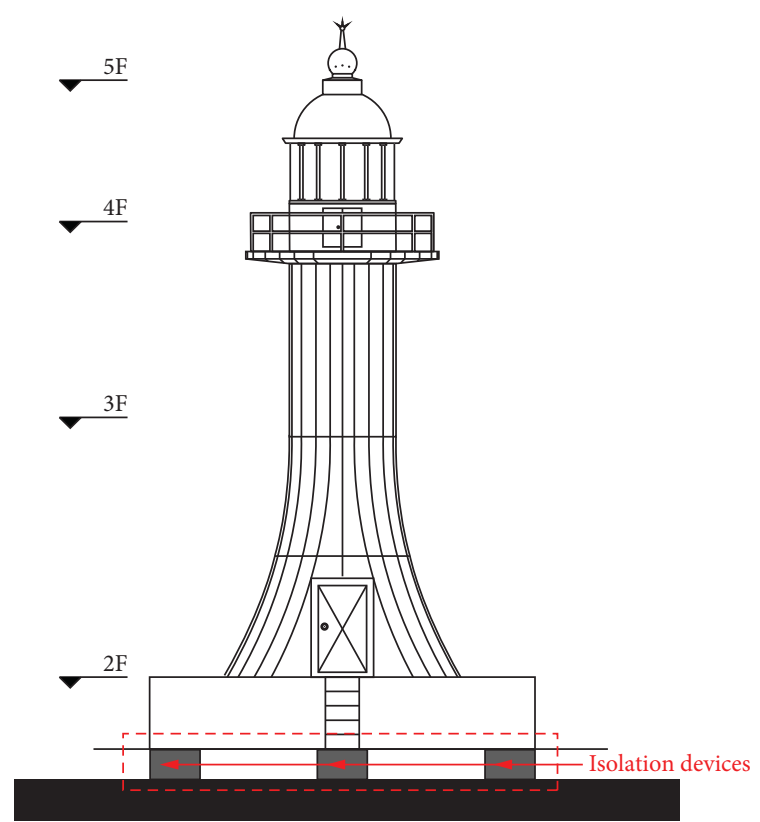

(a)

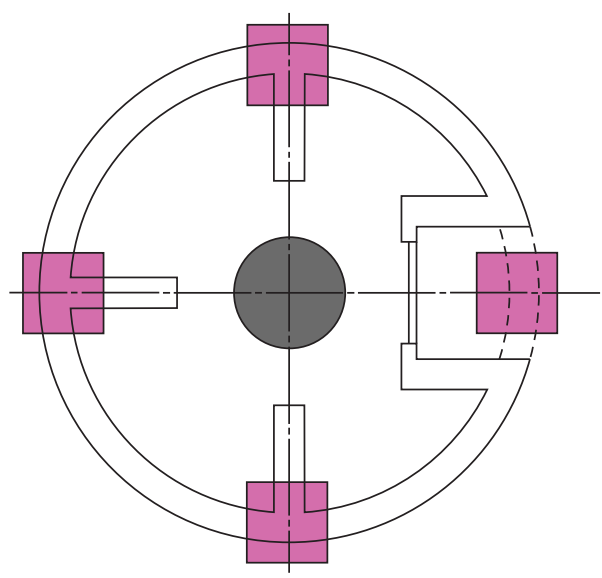

LRB

$\mathrm{RB}$

Figure 7: Section of isolation plan (Case 1). (a) Elevation (b) Plan.

TABLE 4: Displacement of the isolation layer under the wind loads.

\begin{tabular}{lcccc}
\hline Direction & Story & Level $(\mathrm{m})$ & Story height $(\mathrm{m})$ & Maximum displacement $(\mathrm{mm})$ \\
\hline \multirow{4}{*}{$X$ and $Y$} & Roof & 13.9 & 0 & 52.6 \\
& $5 \mathrm{~F}$ & 11.4 & 0.3 & 51.7 \\
& $4 \mathrm{~F}$ & 6.5 & 2.3 & 45.3 \\
& 3F & 1.5 & 5.0 & 41.2 \\
\\
& 2F & 0.4 & 2.0 & 40.6 \\
\end{tabular}

nonseismic reflection at each level of the DBE level. Figure 13(a) shows this graphically. Also, Figure $13(\mathrm{~b})$ is a schematic representation of the analysis result at the MCE level. The nonseismic detailed structure exhibits an increasing displacement response with height of the structure and results in exceeding the story drift in the layer where the lens is located. Conversely, in case of Case 1, only large displacement occurs in the isolation layer, but superstructure has almost similar story displacement, like rigid body motion. At this time, it was confirmed that the maximum displacement of the isolation layer does not exceed the allowable displacement. In Case 2, lens is seismic isolated which is a main component of the lighthouse, and the lens exhibits sufficient seismic isolation effect due to rigid body motion. However, it should be noted that this result is only valid when the safety of the entire lighthouse is secured first. In Case 3 wherein Case 1 and Case 2 are applied, large displacements were observed only in the seismic layer and the lens part due to the double seismic isolation effect. In addition, it was confirmed that the maximum displacement in the seismic isolation device layer does not exceed the allowable displacement.

4.3. Review of Maximum Acceleration. Table 9 compares the results of maximum acceleration of nonseismic and each
Table 5: Damping coefficient (ASCE7-10, Table 17.5-1).

\begin{tabular}{lc}
\hline $\begin{array}{l}\text { Effective damping, } \beta_{\mathrm{D}} \text { or } \beta_{\mathrm{M}} \\
\text { (percentage of critical) }\end{array}$ & $\beta_{\mathrm{D}}$ or $\beta_{\mathrm{M}}$ factor \\
\hline$\leq 2$ & 0.8 \\
5 & 1.0 \\
10 & 1.2 \\
20 & 1.5 \\
30 & 1.7 \\
40 & 1.9 \\
$\geq 50$ & 2.0 \\
\hline
\end{tabular}

seismic isolation cases according to each seismic wave at the DBE level. Figure 14(a) shows this graphically. Also, Figure $14(\mathrm{~b})$ is a schematic representation of the analysis results at the MCE level.

In the nonseismic detailed building, the response acceleration increases with the upper layer, and the maximum value at the lens layer and the uppermost layer shows a high risk of damaging the lens. Conversely, in Case 1, the response acceleration of each layer is almost constant that can be expected to improve the usability. And, it can contribute to preventing the lens damage, a major component of the lighthouse due to internal conduction during the earthquake. 
TABLE 6: RB device details.

\begin{tabular}{lc}
\hline $\begin{array}{l}\text { Roller arrangement (Upper: } \mathrm{a} \times \mathrm{b} \text {, Bottom: } \mathrm{c} \times \mathrm{d}) \\
(\mathrm{ea})\end{array}$ & $\begin{array}{c}\text { (Upper) } 2 \times 6 \\
(\text { Bottom) } 2 \times 6 \\
\text { Roller size }(\mathrm{mm})\end{array}$ \\
Size $(\mathrm{mm})$ & $280 \times 50$ \\
Using load $(\mathrm{kN})$ & $500 \times 140$ \\
Max. load $(\mathrm{kN})$ & 1,200 \\
Axial stiffness $(\mathrm{kN} / \mathrm{mm})$ & 3,000 \\
Coefficient of friction & 0.002 \\
Stroke $(\mathrm{mm})$ & \pm 150 \\
\hline
\end{tabular}

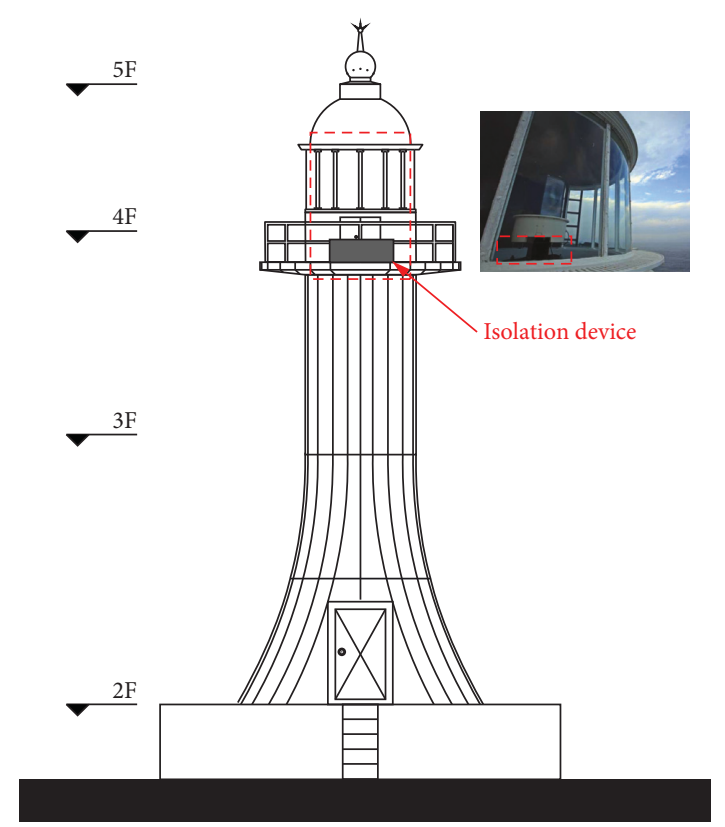

Figure 8: Case 2 elevation.

Also, for all seismic waves, the maximum acceleration of the seismic building shows a tendency to be significantly lower than the maximum acceleration of the base-fixed structure, approximately $80 \%$ in the DBE and approximately $85 \%$ in the MCE. It exceeds the design target reduction (approximately $80 \%$ ), meaning the reduction of the design shear force in the superstructure, making it easy to secure seismic safety by applying seismic isolation technology.

In Case 2, the lens component can obtain reduction effect of acceleration compared to the nonseismic detailed structure, though it is smaller than original design condition (design condition is reduced by $80 \%$ and analysis result is reduced 70\%). And it is possible to secure the safety of the lens, the main component of the lighthouse. Therefore, it is shown that sufficient acceleration reduction effect can be obtained even if a seismic isolation device is installed only at the lower part of the lens, not the entire lighthouse. However, since the lighthouse structure behaves like the earthquake-resistant structure, it is important to note that if the lighthouse built before the earthquake-resistant design is not reinforced with the seismic performance satisfying the current standards, the effectiveness could be reduced.

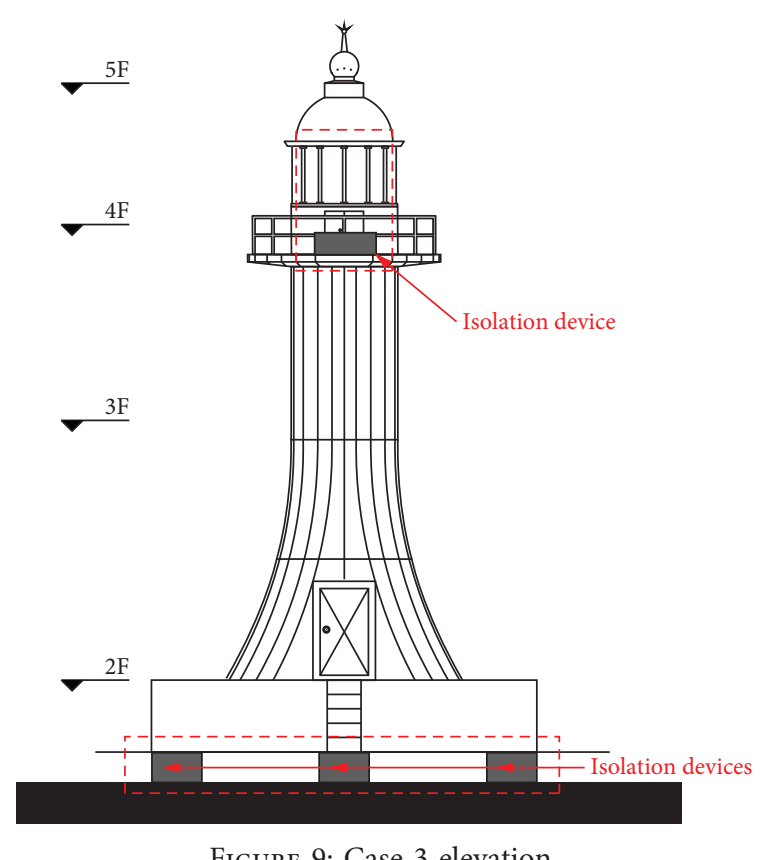

Figure 9: Case 3 elevation.

Case 3 also showed a decrease compared with the nonseismic structure. However, unlike the decrease in the acceleration in the lower isolation layer, the acceleration in the lower isolation layer of the lighthouse lens increases rather than the reduced acceleration level. It is considered that the phase difference at the point showing the maximum value of the acceleration is different due to the different isolation characteristics at the two isolation layers in the double seismic isolation. In this case, there is a possibility that the double seismic isolation effect may be negative. Therefore, further study is needed in this part.

4.4. Review of Story Shear Force. Table 10 compares the results of story shear of nonseismic and each seismic isolation cases according to each seismic wave at the DBE level. Figure 15(a) shows this graphically. Also, Figure 15(b) is a schematic representation of the analysis results at the MCE level.

In Case 1, the story shear force decreased by $43 \%$ at the DBE level compared with that at the foundation and decreased by $43 \%$ at the MCE level. Though it varies on seismic waves, the decrease of story shear force due to seismic isolation means decrease of applied load in member design of superstructure. Therefore, seismic retrofitting of superstructure can be made more economical.

In Case 2, the effect of reducing the story shear force was not greater than that of the entire lighthouse when the whole lighthouse is seismic isolated; it is because the decrease of the layer shear force of the lighthouse lens layer is not so great as to decrease the shear force in the substructure.

In Case 3, the story shear force reduction effect was like Case 1 . However, in the case of the lighthouse lens, it is like the result of Case 2. In the case of such a compact and hollow structure, it is more economically advantageous to adopt the whole seismic isolation than the double seismic isolation system. 


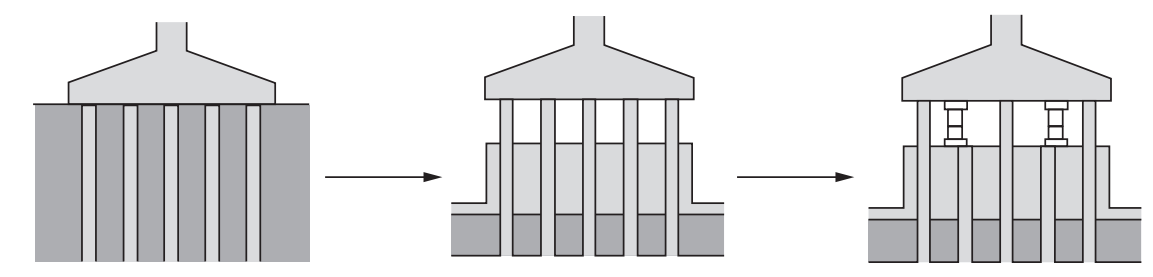

Existing foundation excavation

Foundation construction

Foundation removal and Jack support insert
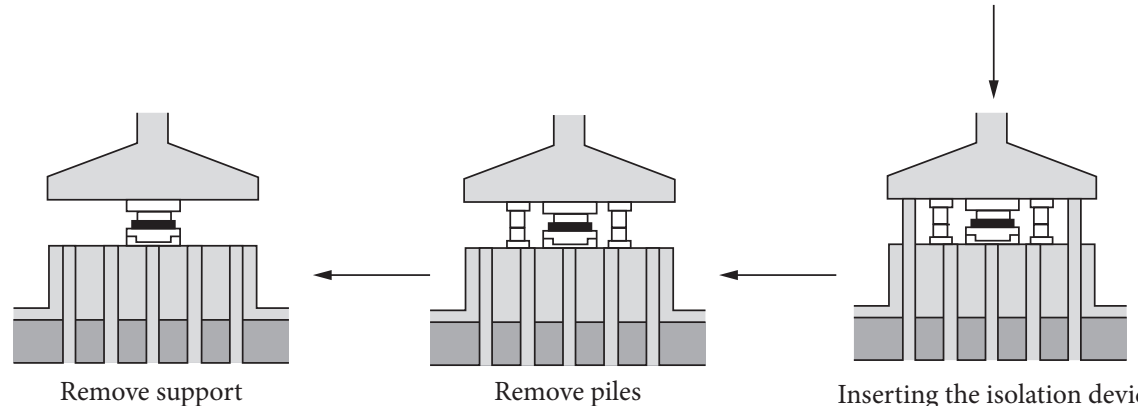

Remove piles

Inserting the isolation device

Figure 10: Isolation device construction.

TABLE 7: Input bedrock earthquake records for selected 7 ground motions.

\begin{tabular}{lccccc}
\hline No. & Event & Country & Year & Station & M \\
\hline 1 & Loma Prieta & USA & 1989 & Pidemont Jr. high school grounds & 6.93 \\
2 & Loma Prieta & USA & 1989 & SF-Pacific heights & 895 \\
3 & Chi-Chi & Taiwan & 1999 & HWA003 & 1,250 \\
4 & Chi-Chi & Taiwan & 1999 & ILA015 & 7.62 \\
5 & Chi-Chi & Taiwan & 1999 & TAP067 & 7.62 \\
6 & Chi-Chi-06 & Taiwan & 1999 & HWA003 & 783 \\
7 & Campano Lucano & Italy & 1980 & Bisaccia & 808 \\
\hline
\end{tabular}

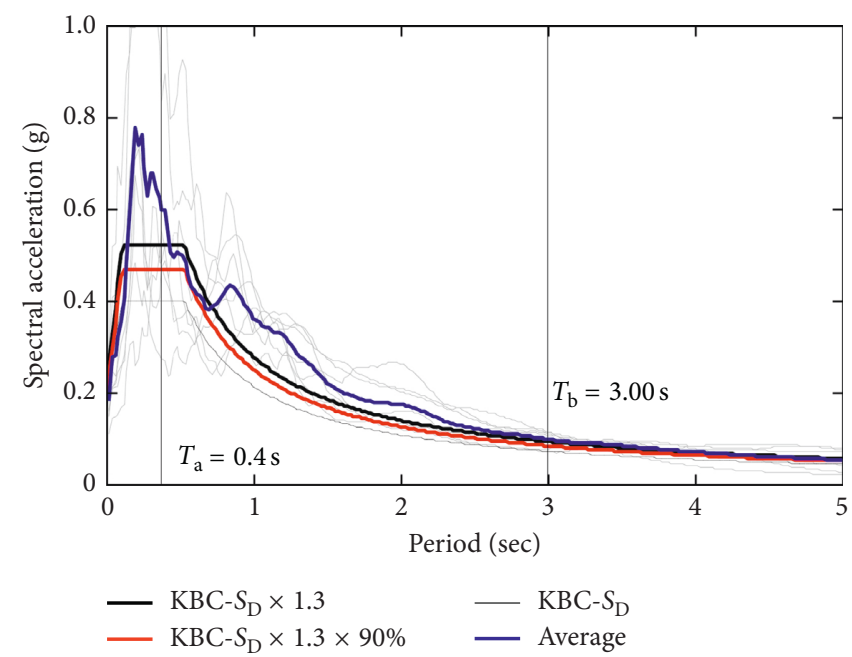

FIGURE 11: Frequency contents of used earthquakes (DBE). 

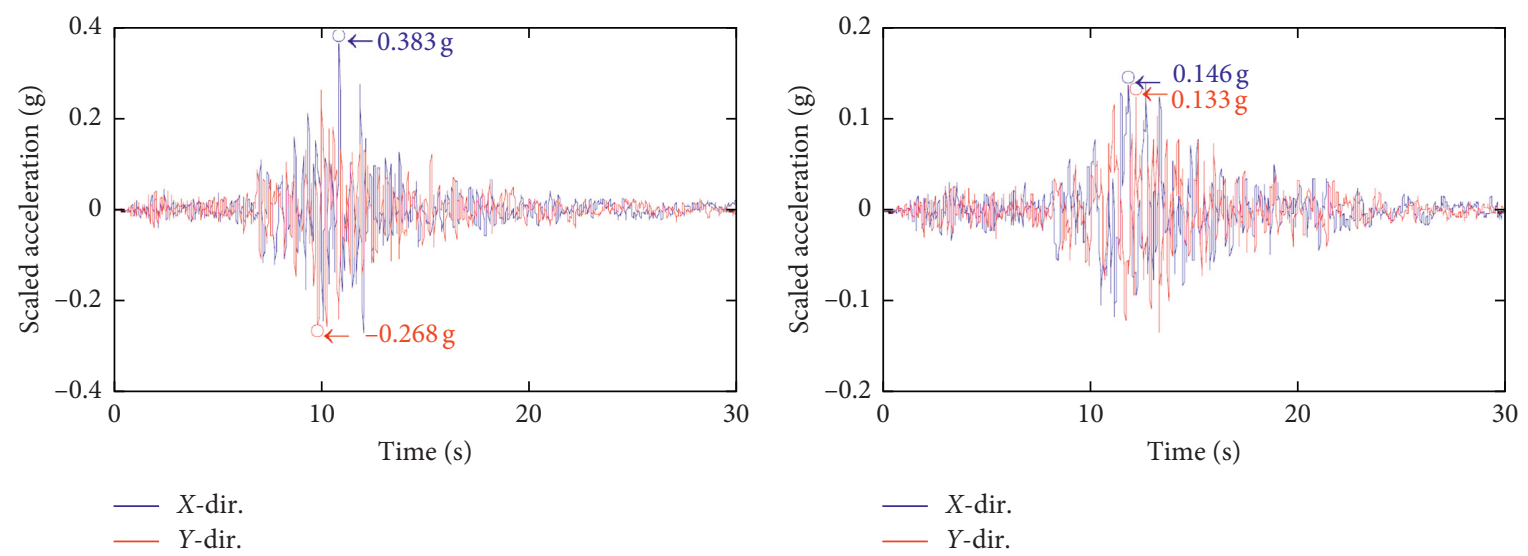

(a)
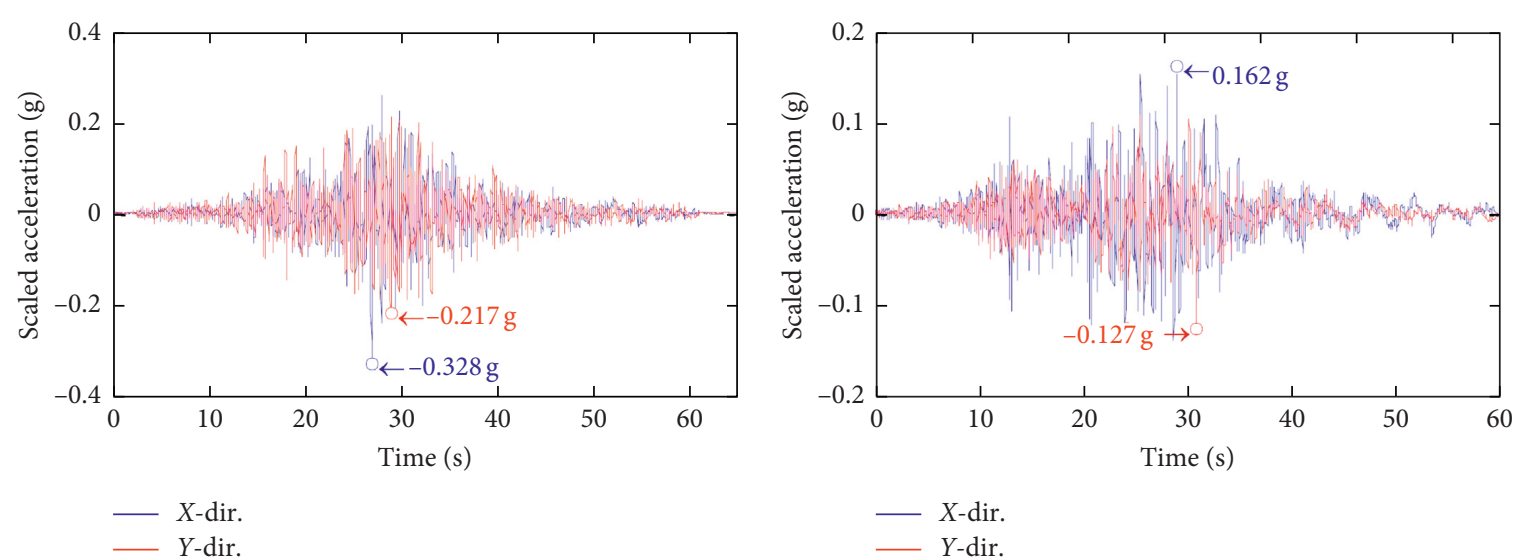

(c)

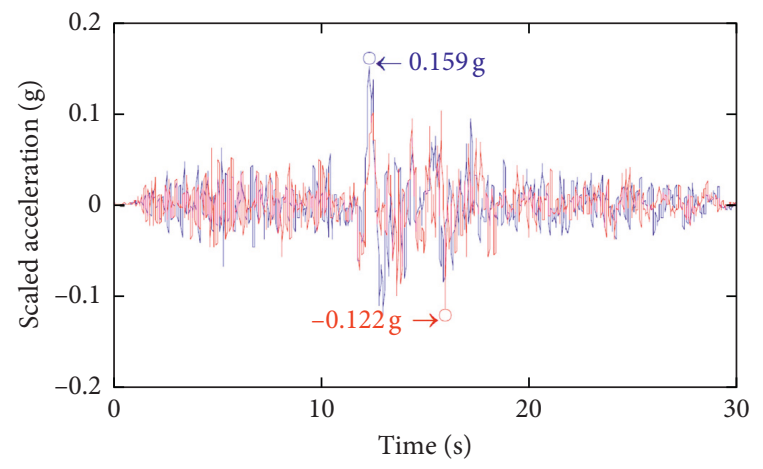

(d)

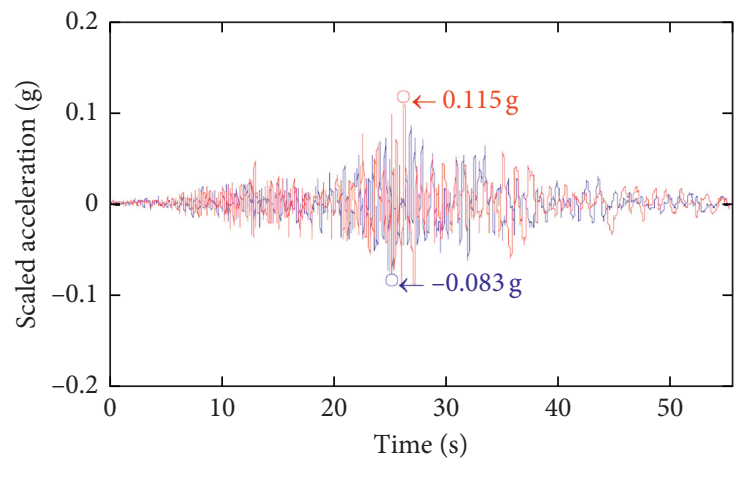

$X$-dir.
$-Y$-dir.

- X-dir.

$Y$-dir.

(e)

(f)

Figure 12: Continued. 


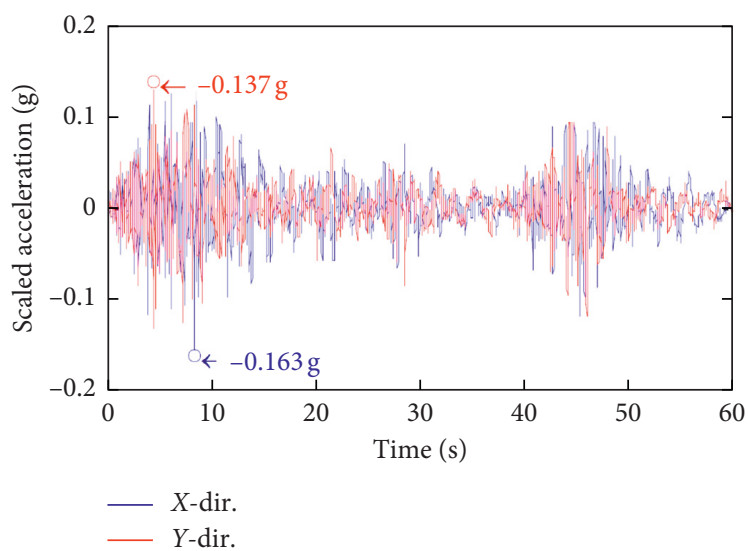

(g)

Figure 12: Acceleration time history. (a) No. 1, (b) no. 2, (c) no. 3, (d) no. 4, (e) no. 5, (f) no. 6, (g) no. 7.

TABle 8: Average maximum displacement under design-based earthquake (mm).

\begin{tabular}{lccccc}
\hline Story & Level & Without isolation & Case 1 & Case 2 & Case 3 \\
\hline $5 \mathrm{~F}$ & 13900 & 2.34 & 105.7 & 69.4 & 171.9 \\
$4.5 \mathrm{~F}$ & 11800 & 1.79 & 105.6 & 1.7 & 171.3 \\
$4 \mathrm{~F}$ & 11400 & 1.24 & 105.5 & 0.7 & 101.9 \\
$3 \mathrm{~F}$ & 6500 & 0.52 & 105.0 & 0.1 & 101.6 \\
$2 \mathrm{~F}$ & 1500 & 0.09 & 104.9 & 0.1 & 101.3 \\
$1.5 \mathrm{~F}$ & 600 & 0.05 & 0.0 & 0.0 \\
$1 \mathrm{~F}$ & 0 & 0.00 & & 0.0 \\
\hline
\end{tabular}

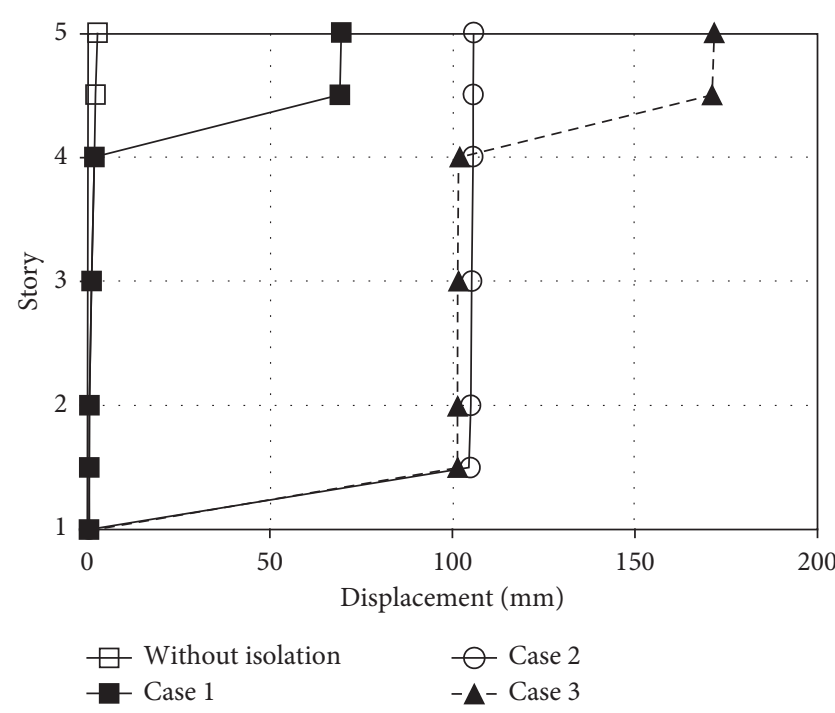

(a)

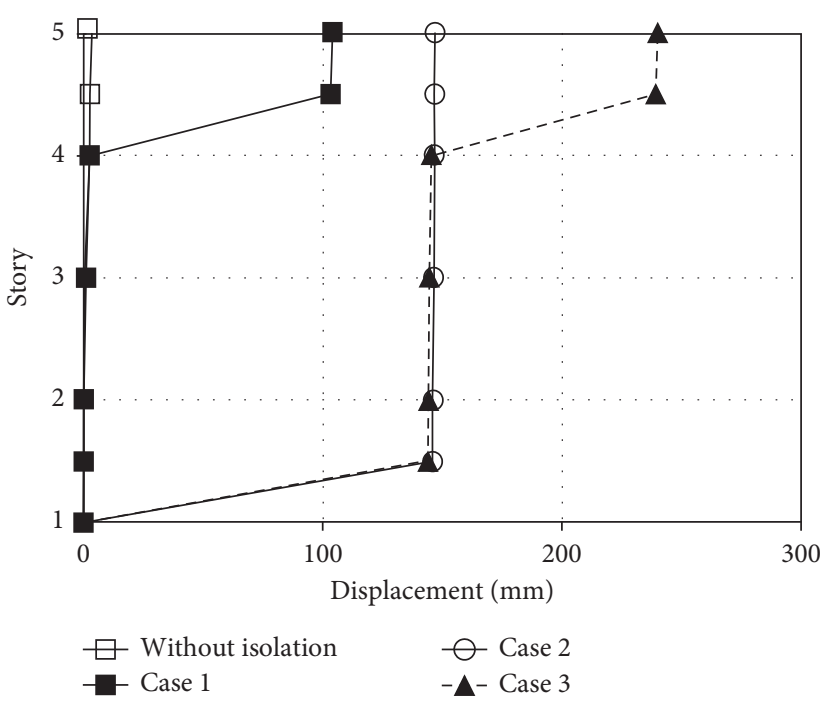

(b)

Figure 13: Average maximum displacement result. (a) DBE. (b) MCE.

TABLE 9: Average maximum acceleration under design based earthquake (mm).

\begin{tabular}{lccccc}
\hline Story & Level & Without isolation & Case 1 & Case 2 & Case 3 \\
\hline $5 \mathrm{~F}$ & 13900 & $10,257.3$ & $1,695.7$ & $3,114.0$ & $3,076.3$ \\
$4.5 \mathrm{~F}$ & 11800 & $6,705.2$ & $1,686.2$ & $6,482.3$ \\
$4 \mathrm{~F}$ & 11400 & $5,289.1$ & $1,676.7$ & $3,490.2$ & $1,061.9$ \\
$3 \mathrm{~F}$ & 6500 & $3,153.2$ & $1,667.5$ & $2,507.2$ & $1,651.6$ \\
$2 \mathrm{~F}$ & 1500 & $2,334.8$ & $1,663.3$ & $2,366.3$ & $1,646.4$ \\
$1.5 \mathrm{~F}$ & 600 & $2,280.1$ & $1,662.5$ & $2,225.3$ \\
$1 \mathrm{~F}$ & 0 & $2,225.3$ & $2,225.3$ & $1,645.6$ \\
\hline
\end{tabular}




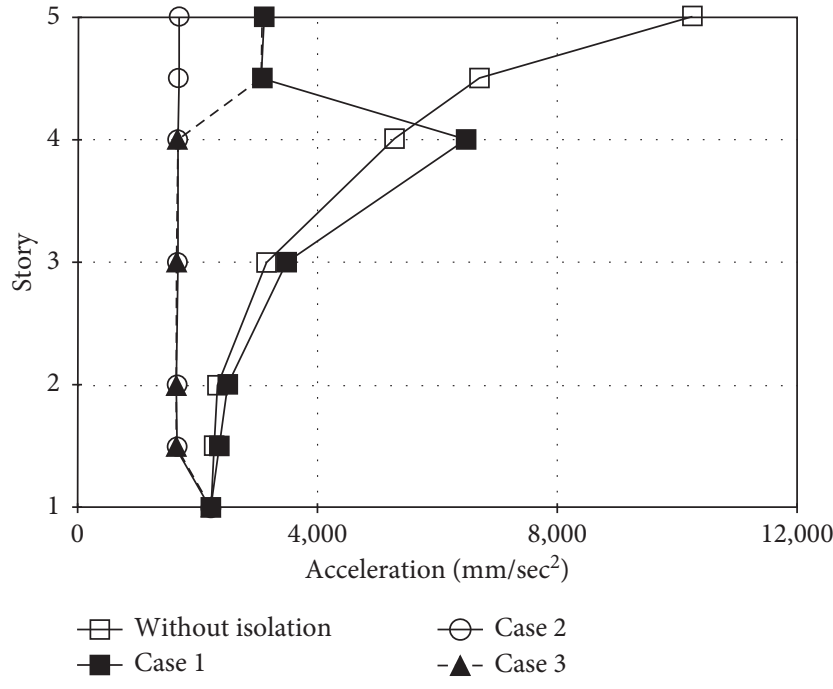

(a)

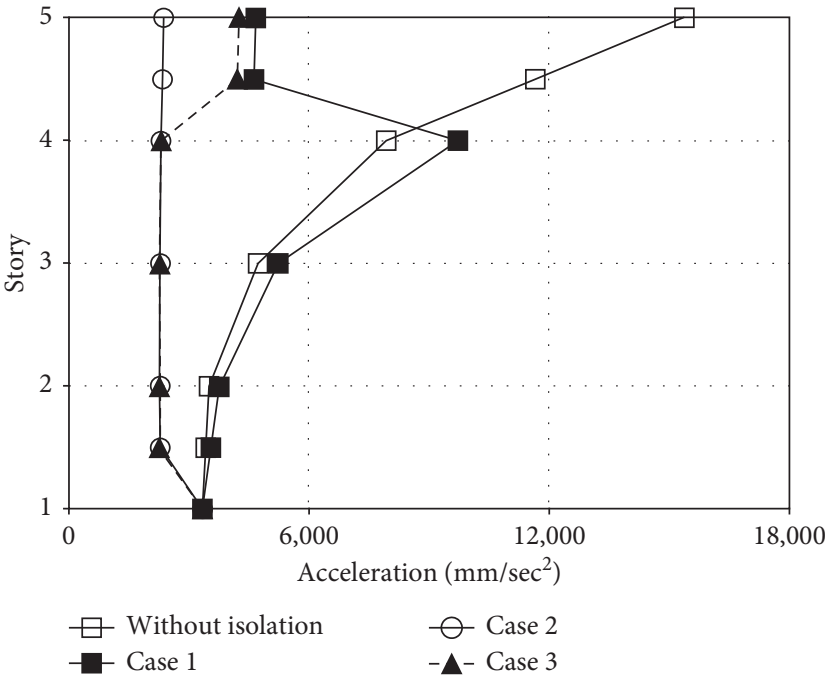

(b)

Figure 14: Average maximum acceleration result. (a) DBE. (b) MCE.

TABle 10: Average story shear under design-based earthquake (mm).

\begin{tabular}{|c|c|c|c|c|c|}
\hline Story & Level & Without isolation & Case 1 & Case 2 & Case 3 \\
\hline $5 \mathrm{~F}$ & 13900 & 0.0 & 0.0 & 0.0 & 0.0 \\
\hline $4.5 \mathrm{~F}$ & 11800 & 3.1 & 0.5 & 2.0 & 2.1 \\
\hline $4 \mathrm{~F}$ & 11400 & 6.2 & 1.0 & 1.7 & 1.9 \\
\hline $3 \mathrm{~F}$ & 6500 & 24.2 & 7.2 & 24.4 & 7.7 \\
\hline $2 \mathrm{~F}$ & 1500 & 51.8 & 22.5 & 54.9 & 22.6 \\
\hline $1.5 \mathrm{~F}$ & 600 & 69.3 & 31.5 & 73.4 & 30.4 \\
\hline $1 \mathrm{~F}$ & 0 & 86.8 & 50.2 & 92.0 & 49.4 \\
\hline
\end{tabular}

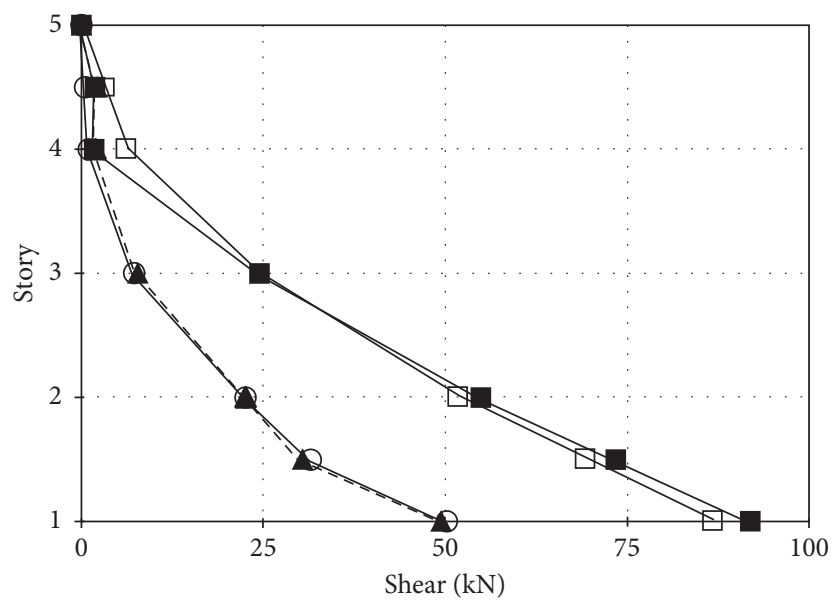

$\square$ Without isolation - Case 1
- Case 2

- - - Case 3

(a)

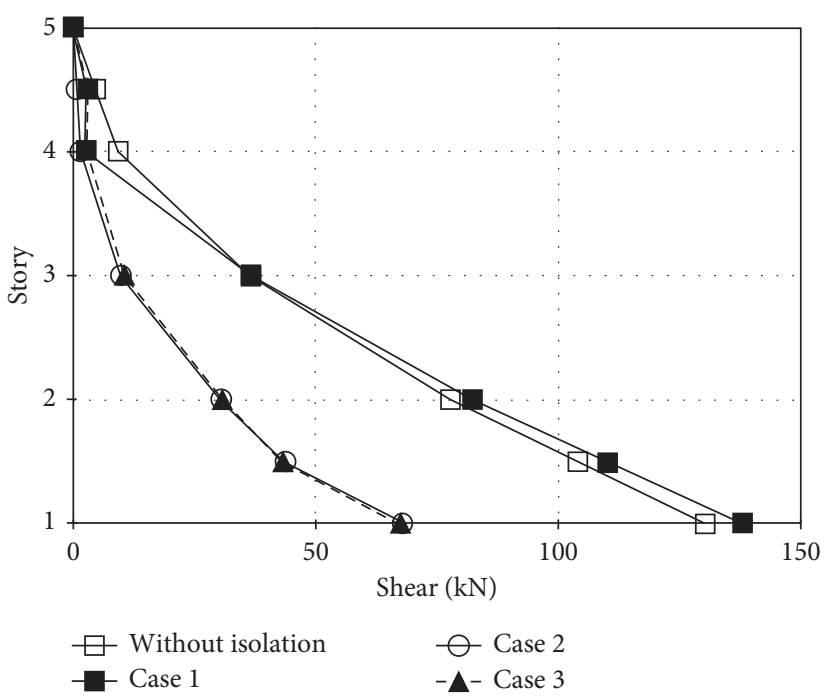

(b)

FIgURe 15: Average maximum story shear result. (a) DBE. (b) MCE. 


\section{Conclusion}

In this study, we propose a method to apply seismic isolation technique to nonseismic detailed lighthouse structures in the coastal area to secure seismic safety of lighthouse structures vulnerable to earthquakes and examine these results on existing lighthouses. The conclusions from the review are as follows:

(1) In the case of a lighthouse structure built before the seismic design criteria were established, it is difficult to apply laminated rubber bearings that is difficult for lengthy periods or lightweight materials. Also, in the case of a system using coil springs, it causes decrease of seismic isolation effect if the load is heavy and changeable. Therefore, it is advantageous to use the geometry of the rail in the case of a structure such as a lighthouse. In addition, it suggested that measures should be applied to achieve a superior seismic effect regardless of the weight of the load, by setting the interval of the seismic period more than 2.5 times of the nonseismic structure.

(2) Also, though the response to the bottom seismic vibration varies depending on the type of ground where the lighthouse is located and the structure of the lighthouse lens, lighthouse seismic device is proposed to secure the necessary required performance as $1 / 5$ of decrease in the response acceleration to the input acceleration of the lens tower base and a displacement response of approximately $100 \mathrm{~mm}$.

(3) As a result of examining the lighthouse structures according to the proposed method, built before the seismic design criteria were established, in Case 1, the seismic isolation effect is improved in terms of maximum displacement response, maximum acceleration, and story shear force compared to nonseismic detailed lighthouse. In Case 2, the seismic isolation effect of the lighthouse lens was sufficient, but the effect of the lighthouse structure was insignificant. This is because the lighthouse structure is a nonseismic designed structure, and it is possible that the lighthouse structure may be destroyed first before the lens is destroyed. Therefore, it should be applied only when the safety of the lighthouse is ensured against earthquake.

(4) In Case 3, a seismic isolation effect is shown compared to the nonseismic structure, but the maximum acceleration increased compared to the case wherein the entire lighthouse was seismic isolated. The reduction of the layer shear force due to the seismic isolation of the lighthouse lens is quite small, so the effectiveness due to the application of the double seismic isolation is insignificant.

\section{Data Availability}

This article is based on experiments, so all the data are kept by the author. These data can be provided to the reader or editor at any time. The data from this thesis can be obtained viatw001@dankook.ac.kr.

\section{Conflicts of Interest}

The authors declare that they have no conflicts of interest.

\section{Acknowledgments}

This research was supported by a grant (code 17CTAPC114966-02) from challenges of the creative program funded by Ministry of Land, Infrastructure and Transport of Korean government.

\section{References}

[1] I. Papayianni and V. Pachta, Damages of Old Lighthouses and Their Repair, Lisbon, Portugal, 2015.

[2] Japanese Maritime Security Testing Research Center, "Seismic capacity of the stone masonry lighthouse at Paphos, Cyprus," International Journal of Innovative Research in Advanced Engineering, vol. 2, no. 1, pp. 67-73, 2015.

[3] L. Giresini and M. Sassu, "Tests results and simple structural analysis of the main lighthouse in the Harbor of Livorno (Italy)," Advanced Materials Research, vol. 834-836, pp. 1299-1303, 2014.

[4] N. Tomita and S. Fujita, "Study on the rocking vibration induced in three-dimensional seismic isolation system," in Proceedings of ASME Pressure Vessels and Piping Conference, vol. 5, Waikoloa, HI, USA, July 2017.

[5] G. A. Auad and J. L. Almazán, "Nonlinear vertical-rocking isolation system: application to legged wine storage tanks," Engineering Structures, vol. 152, pp. 790-803, 2017.

[6] K. Fujita, K. Yasuda, Y. Kanno, and I. Takewaki, "Robustness evaluation of elastoplastic base-isolated high-rise buildings subjected to critical double impulse," Frontiers in Built Environment, vol. 3, 2017.

[7] G. Maddaloni, N. Caterino, and A. Occhiuzzi, "Shake table investigation of a structure isolated by recycled rubber devices and magnetorheological dampers," Journal of the International Association for Structural Control and Monitoring, vol. 24, no. 5, 2016.

[8] N. A. Shaikh and A. S. Kasnale, "Seismic performance for fixed base and base isolated reinforced concrete structure," IJETST, vol. 2, no. 4, pp. 2165-2171, 2015.

[9] S. M. Dhawade, "Comparative study for seismic performance of base isolated \& fixed based RC frame structure," International Journal of Civil Engineering Research, vol. 5, no. 2, pp. 183-190, 2014.

[10] Japanese Ministry of Land, Infrastructure and Transport, Maritime Security Headquarters, "A seismic measures of a large coastal lighthouse," Brief report, Japanese Ministry of Land, Infrastructure and Transport, Maritime Security Headquarters, Tokyo, Japan, 2006.

[11] The Japan Society of Seismic Isolation, The 9th JSSI AwardSeismic Isolation Device for the Lighthouse Lens, The Japan Society of Seismic Isolation, Chicago, IL, USA, 2008.

[12] Y.-S. Chun and M.-W. Hur, "Seismic isolation effects according to set up the isolation period in the medium and low-rise framed building," Journal of KSMI, vol. 14, no. 6, pp. 1-7, 2010.

[13] ASCE SEI, Minimum Design Loads for Buildings and Other Structures, ASCE7-10, American Society of Civil Engineers, Reston, VA, USA, 2010. 


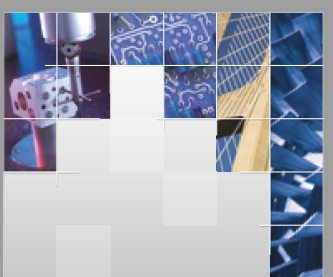

\section{Enfincering}
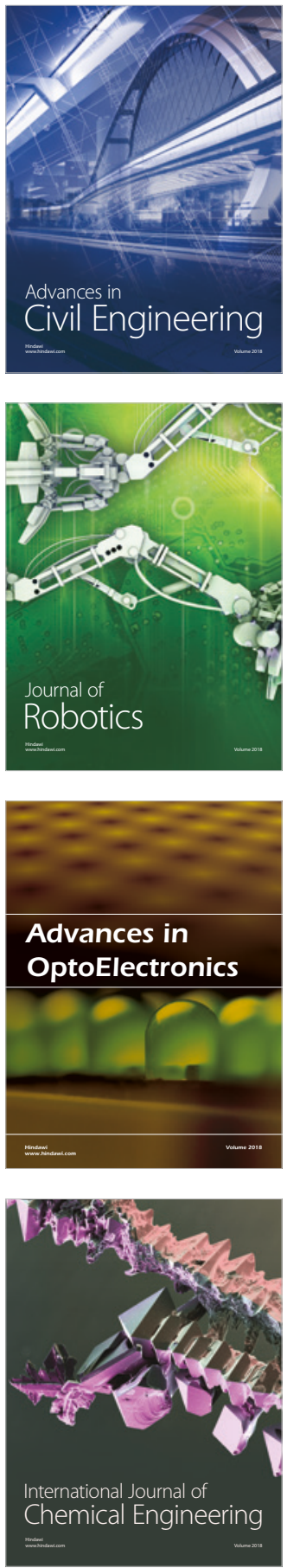

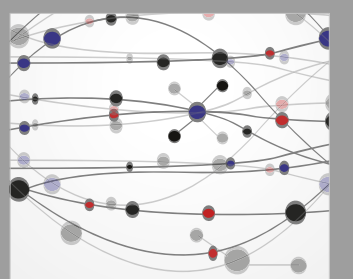

\section{Rotating \\ Machinery}

The Scientific World Journal

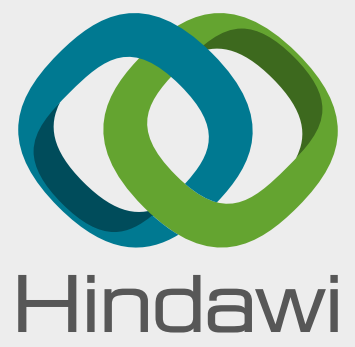

Submit your manuscripts at

www.hindawi.com
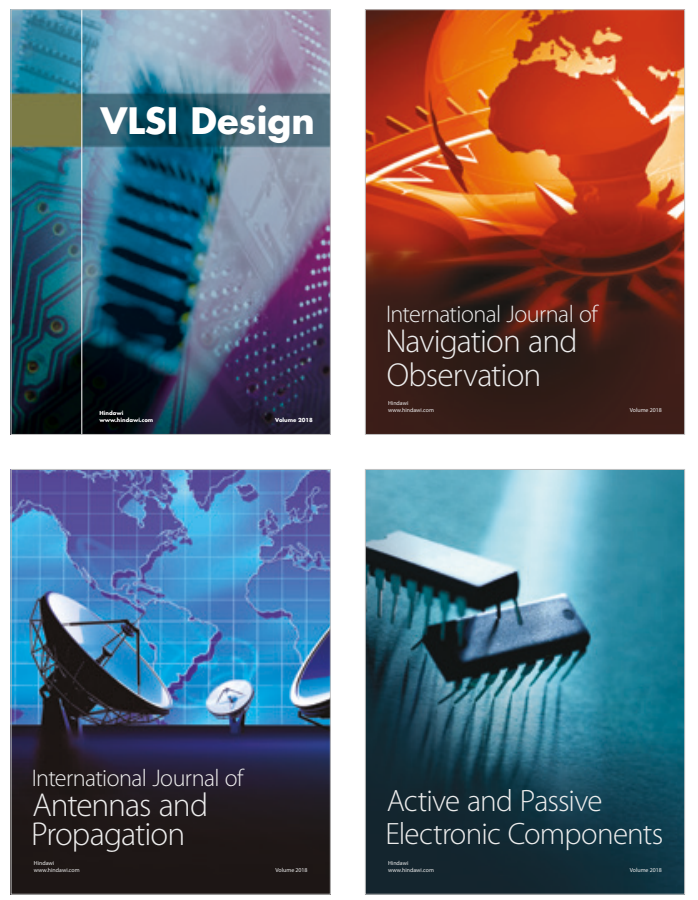
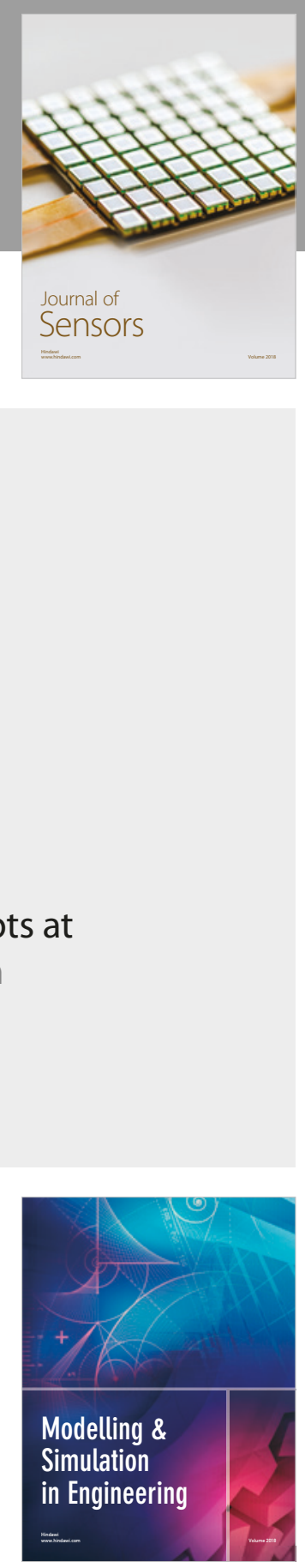

\section{Advances \\ Multimedia}
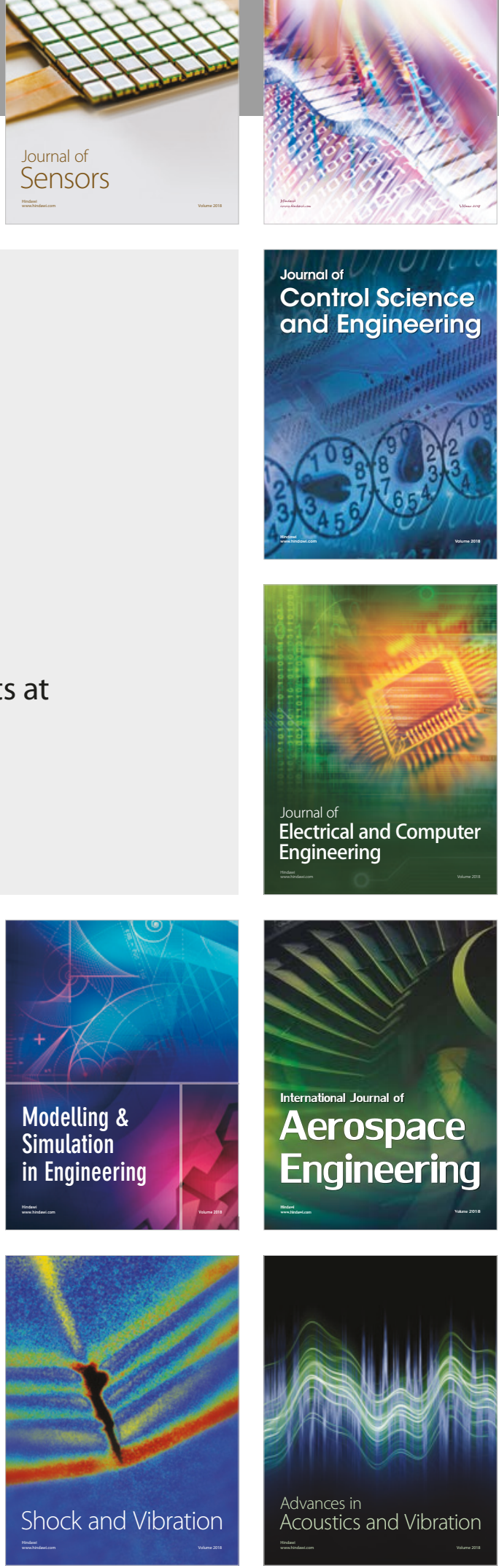